\title{
A descriptive study to assess the burden among family care givers of mentally ill clients
}

\author{
Sachin $\mathrm{S}^{1}$, Suresh $\mathrm{V}^{2}$, Ravindra H.N ${ }^{3}$ \\ ${ }^{1}$ Student, Sumandeep Nursing College, Sumandeep Vidyapeeth, Piparia, Vadodara-391760, Gujarat, India, \\ ${ }^{2}$ Associate Professor, Department of Mental Health Nursing, Sumandeep Nursing College, Sumandeep \\ Vidyapeeth, Piparia, Vadodara-391760, Gujarat, India, \\ ${ }^{3}$ Principal, Sumandeep Nursing College, Sumandeep Vidyapeeth, Piparia, Vadodara-391760, Gujarat, India.
}

\begin{abstract}
Recently, there have been increasing numbers of caregivers who provide care to their chronically ill family members. Care can represent a heavy burden and may put caregivers, who are mostly male under a high level of stress. Culturally, such caregivers are expected to cope and not to complain. The family constitutes an important support system in the care of the mentally ill in the community. Mental health professionals need to be aware of and address the stress borne by the family in caring for patients with mental illness as they treat the patient. The mental health nurse plays very important role in promotion of health, curative and preventive aspects. The study was under taken to" assess the burden among family care givers of mentally ill clients in Dhiraj hospital at vadodara in view to develop an information booklet." Descriptive research design was adopted in this study to assess the level of burden among family care givers of mentally ill clients. Non probability convenient sampling technique was used to select 60 family care givers admitted at Dhiraj hospital, vadodara. The result reveals Overall burden scores of family caregivers revealed that that nearly 27 (45\%) of subject were belong to mild burden. Minority of caregivers $8(13.3 \%)$ belongs to moderate burden. Remaining caretakers $9(15 \%)$ belong to severe burden and 16(26.7\%) belongs to no burden. Chi-square test revealed that there is significant association between the level of burden and selected socio demographic variables.
\end{abstract}

Keywords: burden, caregivers, family, mentally ill client, modified care givers burden assessment scale.

\section{Introduction}

Health is the absolute or ultimate state for all human beings. The World Health Organization defines 'health' as a state of complete physical, mental, social, and spiritual wellbeing, and not merely the absence of any disease or infirmity. ${ }^{1}$

Mental health is defined as the successful adaptation to stressors from the internal or external environment, evidenced by thoughts, feelings, and behaviours that are age appropriate and congruent with local and cultural norms. ${ }^{2}$

Mental illness or mental disorder is a condition that affects thoughts, feelings or behaviors of someone who is strong enough to make social integration problematic, or cause personal suffering. Like other ailments and disorders, mental illness is also a type of disorder that is happening mostly around the brain. That's why it is called as the mental or the mind disorder. ${ }^{3}$

Caregivers play an important role in the management of all the chronic mental illnesses. They may be family members, friends or relatives of the patient. Literature review indicates that caregivers who persistently deal with the patients of chronic mental illness show signs of stress in various forms. Care giving is a timeconsuming responsibility, creating social, emotional, behavioral and financial problems for the caregivers and causes various limitations on their personal life. ${ }^{4}$

A caregiver has been defined as a family member who has been living with the patient, and has been closely involved in his/her activities of daily living, health care, and social interaction for more than a year. ${ }^{5}$

Burden may be defined as the presence of problems, difficulties or adverse effects which affect the lives of psychiatric patients' caregivers. ${ }^{5}$

The World Health Organization (WHO) states caregiver burden as the "the emotional, physical, financial demands and responsibilities of an individual's illness that are placed on the family members, friends or other individuals involved with the individual outside the health care system. ${ }^{5}$

The emotional impact of any psychiatric disorder on family or primary caregivers can vary from frustration, anxiety, fear, depression and guilt to grief. Because care giving is such an emotionally draining experience, caregivers have high rates of depression when compared to the general population. Research on family caregivers of mentally ill relatives has historically focused on negative aspects of care giving, often described as caregiver burden. ${ }^{5}$ 


\section{Statement Of Problem}

"A descriptive study to assess the burden among family care givers of mentally ill clients in Dhiraj hospital at Vadodara in a view to develop an information booklet".

\section{Objectives Of The Study}

1. To assess the level of burden of family caregivers of mentally ill clients.

2. To find out association between level of burden of family care givers and selected demographic variables.

\section{Hypothesis}

H1: There is a significant association between the burdens of the family care givers of mentally ill clients with their selected demographic variables such as age, gender, educational status, occupation, monthly income, marital status, type of family, relation with the client, area of living, duration of care giving and monthly expenditure for treatment.

\section{Material And Method}

Research Approach: The quantitative research approach was adopted in this study. ${ }^{6}$

Research Design: The research design spells out the basic strategies that the researcher adopts to develop information that is accurate and interpretable. ${ }^{7}$

Setting: The present study was conducted in 'Dhiraj Hospital at Vadodara.' The criterion for selecting the setting was feasibility for conducting the study and familiarity of the research investigator with the setting.

Population: In this study, population consisted of caretakers of mentally ill clients. ${ }^{6}$

Target Population: All the accessible population in Dhiraj hospital at Vadodara.

Sample Size And Sampling Technique: In the present study, the sample includes family Caregivers of mentally ill clients in Dhiraj Hospital at vadodara. The sample for the present study was selected by a non-probability convenience sampling technique. Here, the research investigator conveniently decided to select subjects who were judged to be typical of the population. The samples were selected according to the inclusion and exclusion criteria. The sample size for the present study is 60 family caregivers.

Data Collection Technique: A modified care giver burden assessment scale was prepared to assess the determinants the burden of family caregivers. Suggestion of experts in the field and the exposure of investigator in the area of research were considered.

Sampling Criteria: The study had two criteria namely inclusion and exclusion criteria.

\section{Inclusion Criteria}

1. Family caregivers both male and female who were willing to participate in the study.

2. Family caregivers who were present at the time of study in Dhiraj hospital.

3. Family caregivers who can understand Guajarati and English.

\section{Exclusion Criteria}

1. Those who are professional health caregivers.

2. Those who are not caring the mentally ill clients

\section{Development Of Tools}

The tool was developed after:-

1. Review of literature which provided adequate content area and information.

2. Consultation and discussion with experts from nursing personnel, psychiatrist and psychologist.

The details of the tools are described as follows.

Part I: Socio demographic Questionnaire: The socio-demographic questionnaire consisted of 11 items such as age, gender, monthly income, occupation, educational status, marital status, type of family, area of living, and relation with the client, duration of care giving and monthly expenditure for treatment.

Part II: caregiver burden scale: It is a modified care givers burden assessment scale which consisted of 30 items about how family caregivers feel when they are taking care of mentally ill clients. It is used to assess the caregiver's burden level. 
Content Validity: Tool and blue print were submitted to nine experts. The experts were one MD Specialist Psychiatry and 8 professors of Psychiatric Nursing. The Content Validity Index (CVI) across the expert's ratings of each item was calculated. The CVI of 0.75 or more is generally considered to have good content validity. A CVI of 0.86 were found for modified care givers burden assessment scale. ${ }^{8}$

Reliability: The reliability of the tool was tested by split half method by using spilt half method. The reliability result was $r=0.90$. Hence the tool was considered as reliable.

Procedure For Data Collection: Formal permission was obtained from the concerned authorities. The data collection was done within a given period of $11^{\text {th }}$ to $27^{\text {th }}$ November 2013. Research investigator introduced self to the caregivers and gave brief details about the purpose of the study. Planning of time schedule of data collection was done. Each participant was given the consent form so as to ensure their confidence and was assured confidentiality of their responses.

Plan For Data Analysis : For the present study, the data obtained were analyzed in respect to the objectives of the study by using descriptive and inferential statistics. The plan of data analysis was worked out with the experts in the field of statistics and nursing. The plan of analysis was as follows:

1. Organization of data in a master data chart.

2. Tabulation of data in terms of frequencies and percentage.

3. Assess the level of burden by using mean and association by chi square.

Table1: Interpretation of scores for level of burden

\begin{tabular}{|c|c|c|}
\hline SL. NO & SCORES & LEVEL OF BURDEN \\
\hline 1 & $0-22$ & No burden \\
\hline 2 & $23-45$ & Mild burden \\
\hline 3 & $46-68$ & Moderate burden \\
\hline 4 & $69-90$ & Severe burden \\
\hline
\end{tabular}

\section{Descriptive Statistics}

The following were used to draw the following conclusions

Frequency and percentage distribution to analyze the demographic data of caretakers

\section{Inferential Statistics}

Chi- Square test were used to analyze the association between the burdens of family caregivers with selected demographic variables

\section{Results}

The results were computed using descriptive and inferential statistics based on hypotheses and the objectives of the study.

\section{Presentation Of Data}

The descriptive and inferential statistics are used to analyze the data and are represented in the form of tables and diagrams. It is presented under the following headings

Section A: Frequency and percentage of demographic variables of family caregivers.

Section B: Frequency and percentage of level of burden of family caregivers.

Section C: Association between levels of burden of family care givers with selected demographic variables.

\section{Section A: Sample Characteristics Of Care Givers}

It is analyzed by using descriptive statistics and summarized in terms of frequency and percentage.

> Present study indicates that majority of subjects $33.3 \%$ (20) belonged to the age group of 20 - 30 years, $30 \%$ (18) were in the age group of 31-40 years, and $18.3 \%$ (11) were in the age group of $41-50$ years and 51-60 years. 


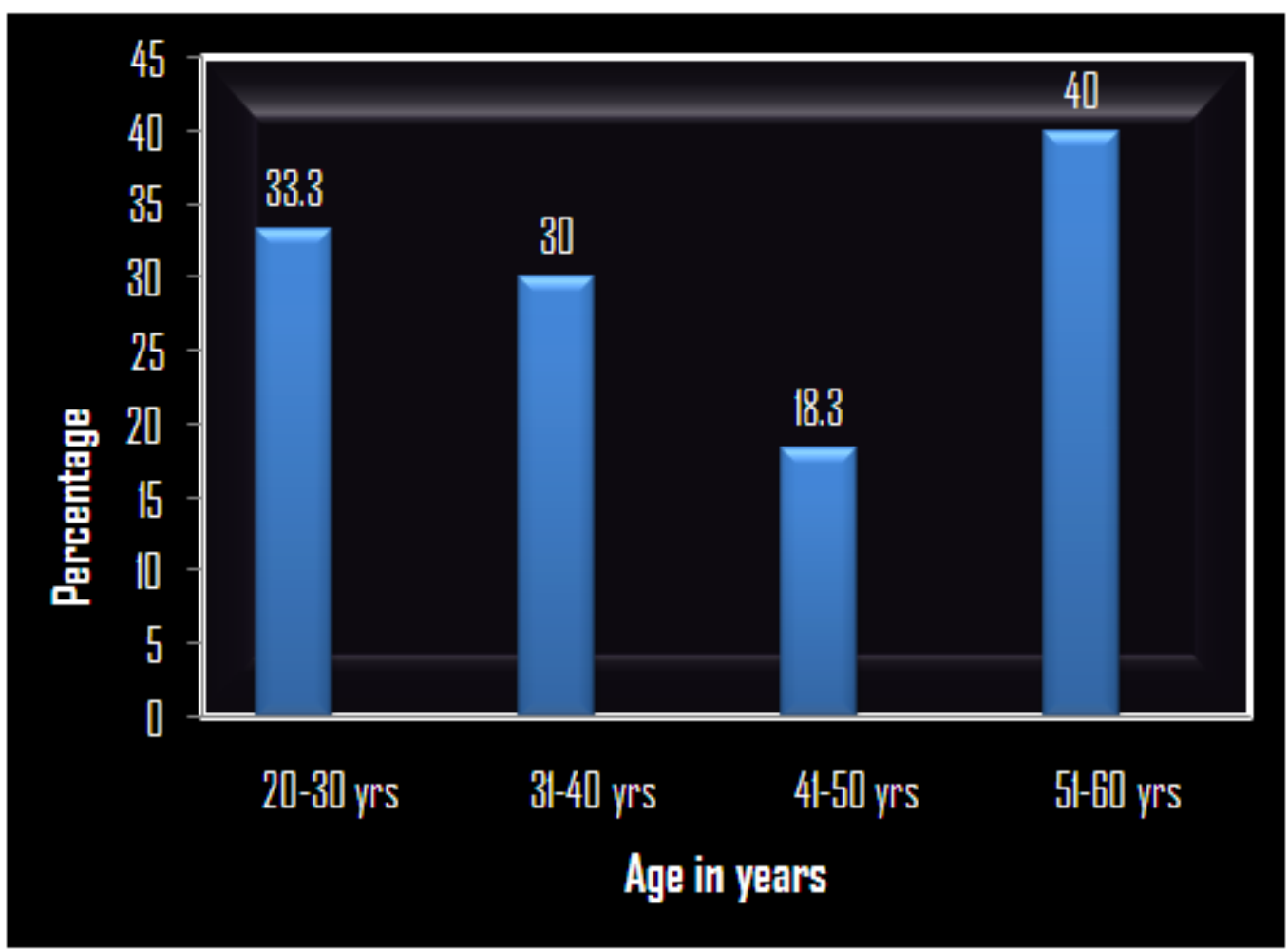

Figure - 1: Bar diagram showing percentage distribution of caretakers according to age in years

$>$ Distribution of the respondents in relation to sex reveals that $53.3 \%$ (32) of respondents were males and $46.7 \%$ (28) of them were females.

$>$ Regarding educational status, most of the subjects $45 \%$ (27) were qualified as secondary and higher secondary, $41.7 \%$ (25) had primary education, $8.3 \%$ (5) belongs to illiterate whereas only $5 \%$ (3) were graduate.

$>$ Regarding occupation, most $41.7 \%$ (25) of the subjects had private job, followed by $38.3 \%$ (23) of subjects had others job and only $3 \%$ (5) of them were had government job.

$>$ Regarding monthly income, nearly half, $30(50 \%)$ had an income of Up to 5000 Rs per month, $21(35 \%)$ of the participants had an income between5001-10000 Rs per month, 7 (11.7\%) of the participants had an income between 10001-15000 Rs and only 2 (3.3\%) of the participants had an income between15001 Rs and above.

$>$ In relation to marital status shows that majority if subjects $50(83.3 \%)$ were married and the remaining 6 $(10 \%)$ were unmarried.

$>$ Regarding type of family, majority of sample 41 (68.3\%) were belonging joint family and rest of them were belongs to nuclear family.

> Distributions of the family caregivers in relation with the family illustrate that, Most of the family caregivers $19(31.7 \%)$ relation belongs to others. Least of the family caregivers $3(5 \%)$ of them were sisters. Remaining family caregivers $12(20 \%)$ belongs to wife and $6(10 \%)$ of family caregivers belong to father and mother.

$>$ Regarding area of living, majority of the family caregivers $36(60 \%)$ staying in rural area, $24(40 \%)$ were staying in urban area.

$>$ Among the Duration of care giving, majority of the family caregivers 35 (58.3\%) fall between 0 to 3 years of care. Minority of the family caregivers $5(8.3 \%)$ fall between $7-9$ years of care. Remaining family caregivers 20 (33.3\%) fall between 4-6 years of care and no family caregivers fall between 10-12 years

$>$ Among the Monthly expenditure for treatment, majority of the family caregivers $27(45 \%)$ spend an amount between 3001-6000 Rs. Minority of the family caregivers $1(1.7 \%)$ spend an amount between 9001 Rs and above. Remaining family caregivers 26 (43.3\%) spend an amount between Up to 3000 Rs; family caregivers $6(10 \%)$ spend an amount between 6001-9000 Rs. 


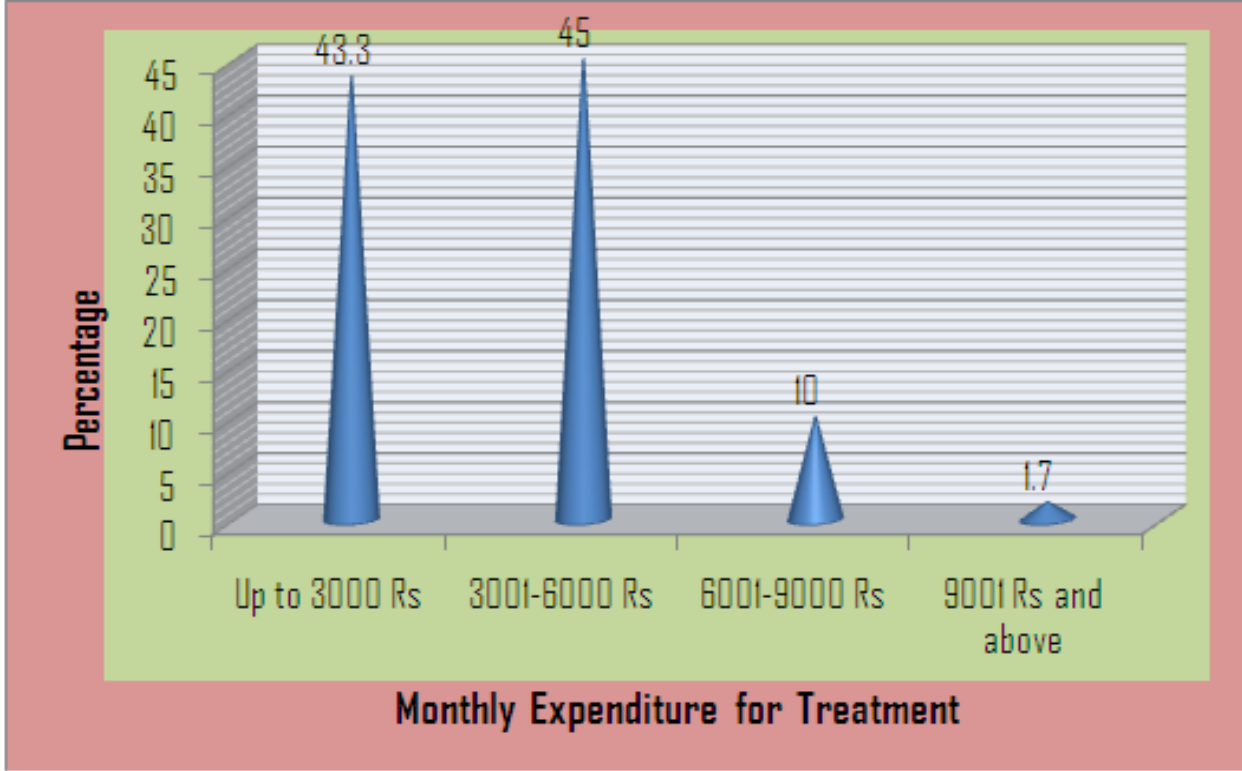

Figure - 2: cone diagram showing percentage distribution of family caregivers according to monthly expenditure of treatment

Section B: Assessment Of The Level Of Burden Of Family Caregivers Regarding Care Of Mentally III Clients

Table 2: Assessment of the level of burden of family caregivers of mentally ill clients.

\begin{tabular}{|c|c|c|c|}
\hline SR. NO & LEVEL OF BURDEN & FREQUENCY & PERCENTAGE \\
\hline 1 & No burden & 16 & 26.7 \\
\hline 2 & Mild burden & 27 & 45.0 \\
\hline 3 & Moderate burden & 8 & 13.3 \\
\hline 4 & Severe burden & 9 & 15.0 \\
\hline & Total & 60 & 100.0 \\
\hline
\end{tabular}

Table 2 depicts that nearly 27 (45\%) of subject were belong to mild burden. Minority of family caregivers $9(15 \%)$ belongs to sever burden. Remaining family caregivers $8(13.3 \%)$ belong to moderate burden and $16(26.7 \%)$ belongs to no burden.

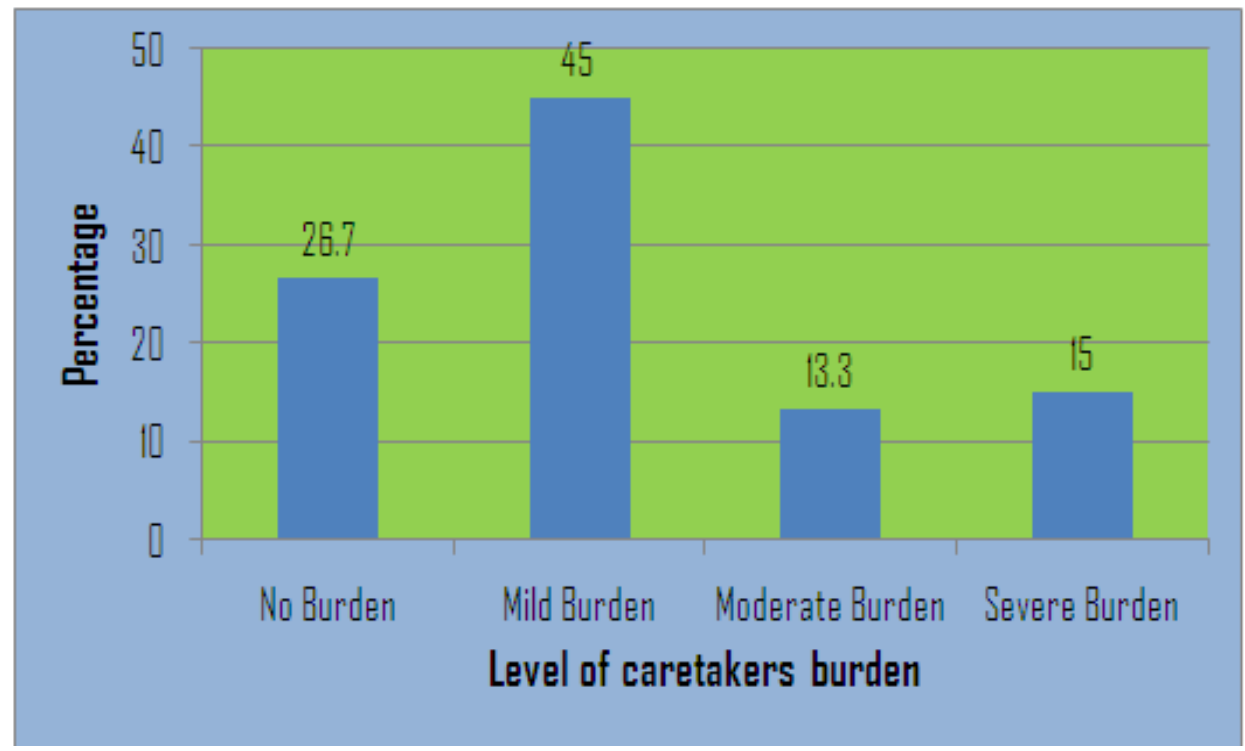

Figure - 3: bar diagram showing percentage distribution level of caretakers burden 


\section{Section C: Association Between Levels Of Burden Of Family Care Givers With Selected Demographic Variables}

$>$ The calculated $\mathrm{X}^{2}$ values 10.614 was more than table value in terms of gender at $\mathrm{P}<0.05$ level of significance. The calculated $\mathrm{X}^{2}$ values 17.821 was more than table value in terms of educational status at $\mathrm{P}<$ 0.05 level of significance. The calculated $\mathrm{X}^{2}$ values 14.247 was more than table value in terms of duration of care giving at $\mathrm{P}<0.05$ level of significance. Since association was found to exist between the level of burden and above mentioned socio-demographic variables. The present study shows association between the level of burden with selected socio demographic variables such as age, occupation, monthly income, marital- status, type of family, relation with the client, area of living, and monthly expenditure for treatment. The calculated $\mathrm{X}^{2}$ values was less than table value in terms of age, occupation, monthly income, marital- status, type of family, relation with the client, area of living, and monthly expenditure for treatment at $\mathrm{P}<0.05$ level of significance. Hence no association was found to exist between the level of burden and above mentioned socio-demographic variables.

$>$ Hence the research hypothesis $\mathrm{H}_{1}$ stated there is a significant association between the burdens of the family care givers of mentally ill clients with their selected demographic variables is accepted.

\section{Discussion}

$>$ The Present study was undertaken to assess the burden among family care givers of mentally ill clients in Dhiraj hospitals at Vadodara. This chapter presents the major findings of this study and discussion in relation to similar studies conducted by other researchers.

$>$ Overall burden scores of family caregivers revealed that that nearly 27 (45\%) of subject were belong to mild burden. Minority of caretakers $8(13.3 \%)$ belongs to moderate burden. Remaining caretakers $9(15 \%)$ belong to severe burden and $16(26.7 \%)$ belongs to no burden.

$>$ The analysis was done for association between burden and with selected socio demographic variables using chi-square test. As the computed chi-square value was lesser than the table value of $p<0.05$ level significance. Hence the research hypothesis $\mathrm{H}_{1}$ shows that there is significant association between the level of burden and selected socio demographic variables.

\section{Conclusion}

$>$ The conclusion drawn from the study includes the level of burden of family caregivers regarding the care of mentally ill clients found that nearly $27(45 \%)$ of subject were belong to mild burden. Minority of family caregivers $8(13.3 \%)$ belongs to moderate burden. Remaining caretakers $9(15 \%)$ belong to sever burden and $16(26.7 \%)$ belongs to no burden.

$>$ The findings of the study state that, there is no significant association between level of burden of family caregivers and selected socio demographic variables except gender, educational status and duration of care giving.

$>$ The student researcher observed that burden among family caregivers is a real problem and there are solutions to the problem such as providing health education, guidance and counseling and different psychotherapy. This will contribute to healthy individual and thereby a healthy family.

\section{Acknowledgement}

I extend my heartfelt gratitude to all for their prayers, support and best wishes which has enabled me to carry out this study.

\section{Nursing Implications}

The investigator has drawn the following implications from the study which is of vital concern to the field of nursing education, nursing service, nursing service, nursing administration and nursing research.

\section{Nursing Education}

> Nurse educator to give importance to currently involving care related to health problems like burden in nursing curriculum.

$>$ In collaboration with the regulation bodies, educational institutions can arrange and conduct workshops and seminars on management of burden as evolving health problem to be tackled.

\section{Nursing Practice}

$>$ Advanced nursing Practice is one of the evolving trends in nursing practice in which definite specified roles of Nurse clinician, nurse practitioner etc are emerging. Studies like present one contribute to 
development of a new specialization itself in nursing of that of nurse counselor a specialist role of nurse who tackles the burden management in all hospital and community setting.

$>$ Nurses as primary care givers have the supreme responsibility in prevention of burden related health complication among family caregivers.

> Psychiatric intervention should include attention to the mental health and recovery of family caregivers in addition to the patient recovery.

$>$ Factors related to different domains of burden are to be identified before planning intervention for family caregivers.

\section{Nursing Administration}

> Nursing leaders must utilize available resources which are technologically sound in teaching the family caregivers through mass health education programmes. Nursing leaders should enhance nursing services through reinforcement of teaching through the readymade video package.

$>$ Professional interaction between the nurses and the public will help to improve professional standards and creates better image in the hospital and community.

> Specialized teaching package in specific topic create interest among public and serve as reference materials.

\section{Nursing Research}

$>$ Efforts can be made by nurse researcher to conduct interactive sessions with family caregivers for maintenance of healthy practices and also to disseminate the finding of research on health problems related to prolonged care of mentally ill client.

$>$ This study will serve as a valuable reference material for future investigators.

\section{Recommendation}

On the basis of the study that had been conducted, certain suggestions are given for future studies

$>$ A long term longitudinal study can be carried out to assess the level of burden among family caregivers regarding the care of mentally ill clients.

$>$ A comparative study can be done in different settings.

> Regular in-service educational programmes should conduct for the family caregivers regarding the prevention and management of burden.

$>$ A study can be done to assess the attitude and practice of family caregivers regarding the care of mentally ill clients.

\section{References}

[1]. K Park, Parks textbook of Preventive and Social Medicine, seventh edition, M/s Banarsidas Bhanot publishers, page no: 12

[2]. Mary C Townsend, Essentials of Psychiatric Mental Health Nursing, third edition, Independent publisher, page no: 4-5.

[3]. http://www.mentalillnessdefinition.com/mental-illness-definition.

[4]. Wahida Anjum, Haroon Rashid Chaudhry, Muhammad Irfan, burden of care in caregivers of patients with schizophrenia and epilepsy, journal of Pakistan psychiatric society, July-December 2010 volume 7 , pages 1-6.

[5]. Swaroop N1, Shilpa Ravi, B. Ramakrishna Goud, Maria Archana, Tony M Pius, Anjali Pal, Vimal John, Twinkle Agrawal, Geetha Jayaram, burden among caregivers of mentally- ill patients: a rural community - based study, International journal of research and development of health, April 2013 vol 1(2), pages29-34.

[6]. http://www.ias100.in/daily-dose-india's-resolution-on-mental-health-adopted-at-world-health-assembly-889.html.

[7]. Kothari CR, Research methodology: methods and techniques: $2^{\text {nd }}$ Ed. New Delhi: new age international publishers; 2004 . p. 97 112 .

[8]. Terrce EW, Elements of research in nursing: $3^{\text {rd }}$ ed. Mosby company: London. p. $67-75$

\section{Corresponding author:}

\section{Mr. Sachin S,}

M.Sc. Student,

Sumandeep Nursing College,

Sumandeep Vidyapeeth,

Vadodara-391760, Gujarat, India,

Contact no: 8141817623.

E-mail: sachu3259@gmail.com 